\title{
Urban Planning Analyses of Refugee Camps, Jabalia as Case Study-Gaza Strip, Palestine
}

\author{
Dr. Usama Ibrahim Badawy ${ }^{1}$, Dr Ra'ed A. Salha ${ }^{2}$, Dr. Muain Qasem Jawabrah ${ }^{3}$, Amjad Jarada ${ }^{4}$ \\ Mohammed A. EL Hawajri ${ }^{5}$
}

\author{
${ }^{1}$ Former Professor of Architecture, Birzeit University Palestine, works currently at UNRWA \\ ${ }^{2}$ Assistant Professor, Islamic University of Gaza in Geography and GIS Palestine \\ ${ }^{3}$ Assistance Professor, Architecture Department, Birzeit University Palestine \\ ${ }^{4}$ Researcher in Infrastructure Planning and Development works currently at UNRWA, G, \\ ${ }^{5}$ Researcher Geography subjects, works currently as teacher by the Ministry of Education
}

\begin{abstract}
The Gaza Strip is a tight area with more than 1.8 million inhabitants. Since the beginning of the last century, and as other Palestinian areas, Gaza Strip was subject to direct occupation. The occupation tightened laws and regulations and increased obstacles, meanwhile it established settlements in a method that besieges existing Palestinian urban areas and leads them to develop in a way that serves the occupation, particularly the security side. This research begins with background information on Palestinian refugees in Gaza, sees that camp Improvement Strategies should called for adoption of the future urban planning, increasing the accommodation capacity of the built-up area, activating the environmental resources protection laws and played down the issue of the land properties when preparing the comprehensive plans. In this study reviews options for addressing the problems faced by Palestinian refugees in Gaza, Recommendations: After discussing the topic through a analyses of the Current Conditions, Land availability, Population distribution, Land requirements, Overcrowding, Public Spaces problems inside the camps, Sustainability in Gaza Strip, socio-economic situation , Unemployment problem and Population density in Jabalia Camp. The most urgent priorities in jabalia refugee camp are: Renovation and expansion of shelters, improvement of the infrastructure, especially the asphalting of streets and improvement of Places and open Spaces areas inside the camps. It is necessary that such improvement should have a solid economic feature creates real job opportunities that contribute in economic development, reduce high unemployment rates in the Strip and maintain natural resources as a national asset for the coming generations.
\end{abstract}

Keywords: Land Ownership Structure, Population distribution, Overcrowding, Public Spaces

\section{Introduction}

After the return of Palestinian authorities to the occupied territories in 1994, and forming the specialized ministries, several attempts were performed to have strategic plans to overcome the housing problem in Gaza, an area of one the highest dense populations in the world. These attempts were faced by scheduled destruction policies made by the Israeli's crowned by drastic wars that was launched on Gaza stripPalestine in 2009, 2012 and 2014 and has caused a huge destruction in the civil infrastructure, created fragmented neighborhoods, thousands of people left homeless resulting in significant casualties, particularly on the housing sector. This study will examine various factors with reference to planning and designing tools for urban planning problems and their solution, which can offer a new vision for a sustainable improvement for the refugees, camps in general and specially jabalia as a case study.

\subsection{Location of the Study Area}

Gaza Strip constitutes the south west part of Palestinian coastal plain of Mediterranean sea the strip is confines between the Mediterranean sea in the west, Sinai of Egypt in the south, Negev desert in the east and green line in the north. The Gaza strip area is about $365 \mathrm{~km} 2$ [1]. The length is about $41 \mathrm{~km}$ on the western Mediterranean cost and the width varying from 7 to $12 \mathrm{~km}$. Gaza Strip is located in an arid to semi-arid region. It is located on a latitude of 310 16" to 31o 45" North and 34o 20 to 34o 25 East. The study area in Jabalia Camp and the landfill is located closer to green line boundaries [2] see related figure1.

\subsection{Climate of the Study Area}

The climate in Gaza strip has characteristically semi-arid climate, and is located in a transitional Zone between a temperature Mediterranean climate to the west and north, and arid Negev and Sinai deserts to the east and south .There are two well-defined season: the wet season starting in October and extend through April , and the dry season from April to September . The average daily temperature in the Gaza strip range from $26^{\circ} \mathrm{C}$ in the summer to $12^{\circ} \mathrm{C}$ in winter with the average daily maximum temperature range from 29 ${ }^{\circ} \mathrm{C}$ to $17{ }^{\circ} \mathrm{C}$, and the minimum temperature range from 21 ${ }^{\circ} \mathrm{C}$ to $9{ }^{\circ} \mathrm{C}$ in the summer and winter respectively (GMS,2009). Mean daily evaporation ranges between (216.3) $\mathrm{mm}$ per day in July and December respectively [3]. 


\section{International Journal of Science and Research (IJSR)}

ISSN (Online): 2319-7064

Index Copernicus Value (2013): 6.14 | Impact Factor (2015): 6.391

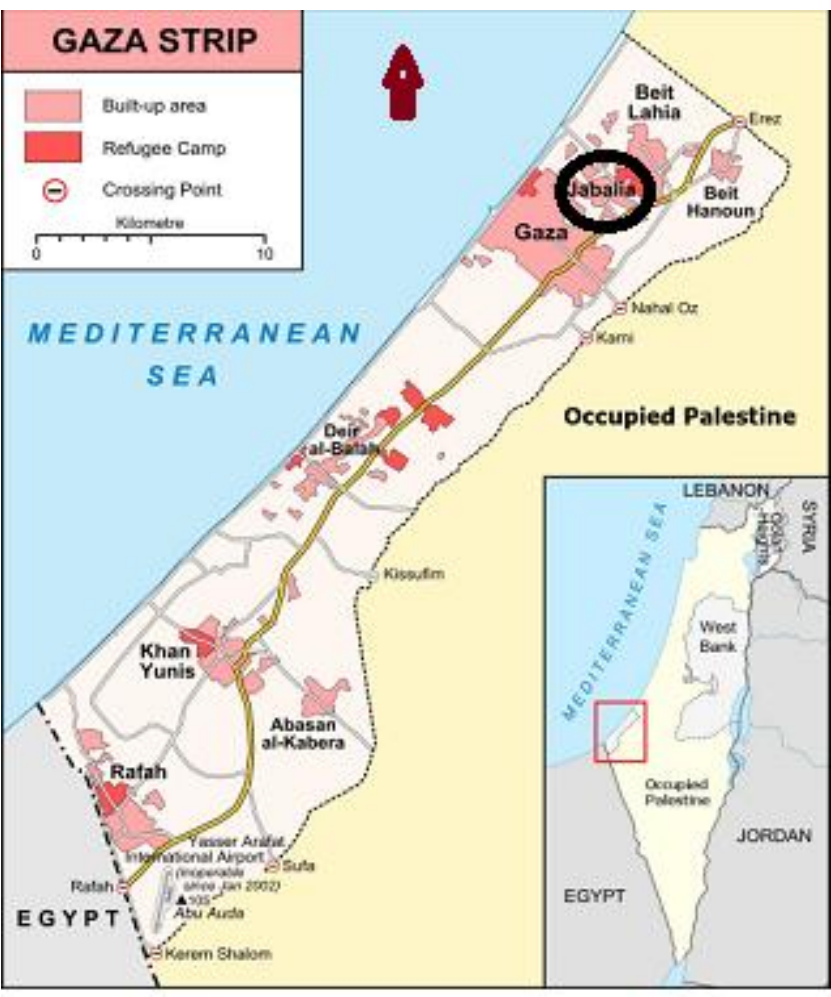

Figure 1: Map of Gaza Strip includes refugee camps, border crossings, major cities, and towns. , Source: Ministry of Local Government, 2015 (reworked by authors)

\section{Climate of the Study Area}

The climate in Gaza strip has characteristically semi-arid climate, and is located in a transitional Zone between a temperature Mediterranean climate to the west and north, and arid Negev and Sinai deserts to the east and south .There are two well-defined season: the wet season starting in October and extend through April , and the dry season from April to September . The average daily temperature in the Gaza strip range from $26^{\circ} \mathrm{C}$ in the summer to $12^{\circ} \mathrm{C}$ in winter with the average daily maximum temperature range from 29 ${ }^{\circ} \mathrm{C}$ to $17^{\circ} \mathrm{C}$, and the minimum temperature range from 21 ${ }^{\circ} \mathrm{C}$ to $9{ }^{\circ} \mathrm{C}$ in the summer and winter respectively (GMS,2009). Mean daily evaporation ranges between (216.3) $\mathrm{mm}$ per day in July and December respectively [3].

The Gaza Strip is $365 \mathrm{~km}^{2}$ with total population 1.8 million is located on the south eastern coastal of the Mediterranean Sea, on the east and north Israel borders it, on the south bordered by Egypt and on the west by the area and its boards, and delimiting lines, first came into existence years ago in 1948 after the first Arab- Israel war. The Strip is part of the Palestinian coastal plane in Southwest Palestine where it forms along narrow rectangle. Its length is about $45 \mathrm{k} \mathrm{m}$, the width $6 \mathrm{~km}$ in the north, with maximum $12 \mathrm{~km}$ at south. The broad population of Gaza is strongly influenced by political development, which have played a significant role in growth and population distribution. A new pattern of settlement evolved with the formation of the eight refugee camps after 1948.The population of Gaza before 1948 was estimated about 80,000, during the two decades from 19481967 the population rose to 454,900 . As result of the unique political situation of Gaza there has been threeadministration period. [4]:

1)The Egyptian period from 1948-1967

2)The Israel occupation period from 1967-1994

3)The Palestinian Authority from 1994 up to date. Gaza Strip economic depends mainly on agriculture, fishing, small industries, and labour exchange with Israel. (see related figure2\&3)

\section{Establishment of Jabalia camp}

Camp surface area expansion records Jabalia

After 1948, the Quaker organization provided basic commodities to Palestine refugees. UNRWA then transitioned into its humanitarian and relief role, distributing tents to the refugee population. In 1949, the camp's total area was 1.4 square kilometers with 35,000 refugees. In 1952, UNRWA built the first traditional halls using clay and cement roofing. The maximum area of a room was $9 \mathrm{~m}$ by 2 $\mathrm{m}$; this room and yard space was assigned for one family consisting of 5 individuals. As the number of refugees increased, more shelters were built. A health clinic, with walls composed of compressed asbestos, was built to provide health services [5].

Table 1: Jabalia Camp Areas for Various years, Source UNRWA, 2015. *dunum=1000m2

\begin{tabular}{|c|c|c|}
\hline Year & Camp Area(dunum) & Source \\
\hline 1949 & 1400 & UNRWA \\
\hline 1960 & 1049 & UNRWA \\
\hline 1997 & 1480 & UNRWA \\
\hline 2010 & 1310 & UNRWA \\
\hline
\end{tabular}

From 1967 to 1993, several main housing projects were implemented. When hundreds of Palestinian shelters were demolished for road construction, more than 2,200 families were transferred from Jabalia camp to Nazzleh and the Bait Lahiya project. Since 25 January 2006, everything dramatically changed. The Gaza Strip is considered a highrisk area and all crossings have been closed or limited see related table1. An unavailability of industrial materials has stopped all industrial work. Consequently, all construction related projects were partially stopped.Jabalia with 88,700 residents is the largest and most densely populated camp in the Gaza Strip. It is north of Gaza town on $8 \mathrm{~km}^{2}$ sites, adjacent to Jabalia village. Initially, tents housed the original 35,000 refugees who fled from villages in southern Palestine. Jabalia has 42 UNRWA school (2 single shift, the rest double shift), an UNRWA health center.

\subsection{The Housing sector situation is complicated by}

The fact that Gaza is under a complete siege and the construction material is not available in the local market. We believe that it is not enough to rebuild what has been destroyed in the fighting; rather it should establish a strategic plan towards more sustainable developments for the Palestinian society in the Gaza Strip. Indeed, if postwar reconstruction is to be truly effective, it must also involve reconstructing social structure, culture, and human 


\section{International Journal of Science and Research (IJSR) \\ ISSN (Online): 2319-7064}

Index Copernicus Value (2013): 6.14 | Impact Factor (2015): 6.391

relationships. As a result of poverty levels, for most camp residents, it is not easy to purchase additional land outside of the camp to expand homes. To address this, in 1980, they started to build multi-story buildings to gain extra space for

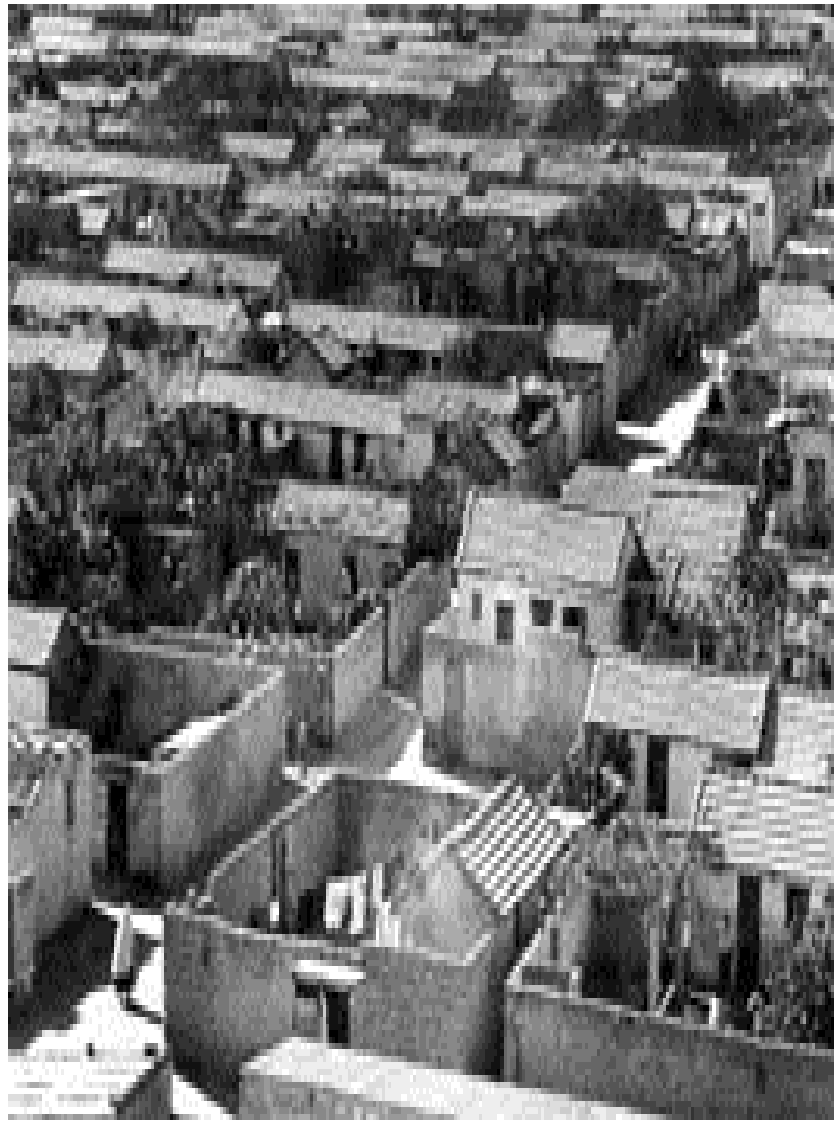

Figure 2: Jabalia camp 1972, source UNRWA public relation, 2015.

families, particularly after increased household numbers with married sons. Most multi-storey buildings are concentrated on the sides of main streets in the camp. Other shelters were not rebuilt because the area's narrow paths restrict access for building machines and vehicles. Because of these construction efforts, there are a variety of styles and sizes of buildings in the camp.

The place of origin of most jabalia refugees as followed Majdal, Burir, Hirbia, Yibna, Samsam, Barbara, Hamma, Barbara, this all are villages which was before the war of 1948 see related table2.

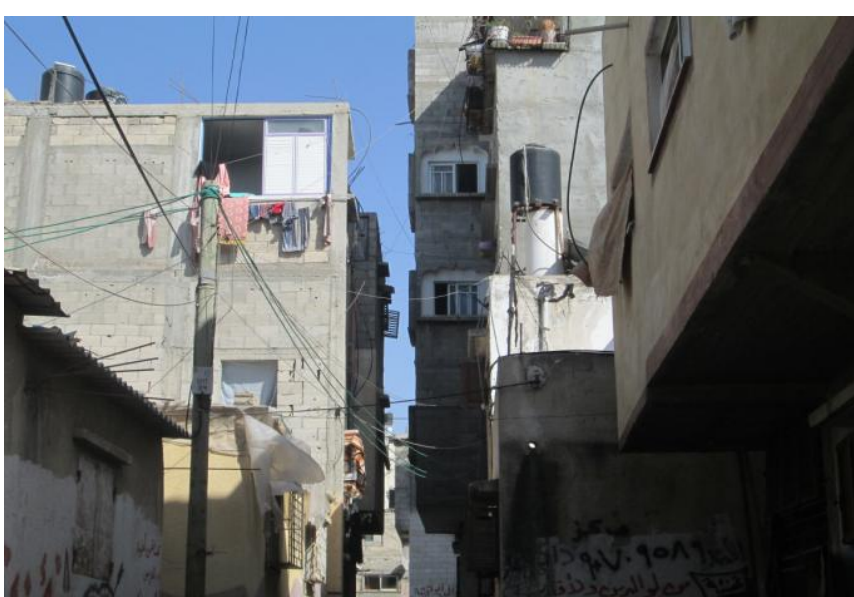

Figure 3: Jabalia camp Narrow Street inside the camp blocks , Source authors,2016.

Table 2: Main villages of origin inhabitant of Jabalia camp, source; UNRWA Gaza RSSD 2015

\begin{tabular}{|c|c|c|c|}
\hline Origin & Total & Male & Female \\
\hline MAJDAL & 14092 & 7300 & 6792 \\
\hline BUREIR & 7548 & 3885 & 3663 \\
\hline HIRBIYA & 7075 & 3670 & 3405 \\
\hline YIBNA & 5042 & 2590 & 2452 \\
\hline SUMSUM & 6786 & 3415 & 3371 \\
\hline BARBARA & 4729 & 2413 & 2316 \\
\hline NI'ILYA & 4164 & 2172 & 1992 \\
\hline HAMAMA & 4614 & 2321 & 2293 \\
\hline NI'ILYA & 4164 & 2172 & 1992 \\
\hline Others & 56810 & 0 & 0 \\
\hline
\end{tabular}

\subsection{Vertical growth and saturation}

As a result of poverty levels, for most camp residents, it is not easy to purchase additional land outside of the camp to expand homes. To address this, in 1980, they started to build multi-storey buildings to gain extra space for families, particularly after increased household numbers with married sons. Most multi-storey buildings are concentrated on the sides of main streets in the camp. Other shelters were not rebuilt because the area's narrow paths restrict access for building machines and vehicles.

Because of these construction efforts, there are a variety of styles and sizes of buildings in the camp.

Due to the increase in population size, families began to build additional rooms to their shelters at the expense of street width. Families built outwards because there were no other available vacant spaces for expansion. Gradually, street width decreased from $24 \mathrm{~m}$ to a maximum of $5 \mathrm{~m}$ and, for paths, $2 \mathrm{~m}$ wide. A large percentage of families purchased land near the camp to build their own shelters. This helped to expand the camp's layout mainly to the east and west.

As a result of poverty levels, for most camp residents, it is not easy to purchase additional land outside of the camp to expand homes. To address this, in 1980, they started to build multi-storey buildings to gain extra space for families, particularly after increased household numbers with married sons. Most multi-storey buildings are concentrated on the sides of main streets in the camp. Other shelters were not 


\section{International Journal of Science and Research (IJSR) \\ ISSN (Online): 2319-7064}

Index Copernicus Value (2013): 6.14 | Impact Factor (2015): 6.391

rebuilt because the area's narrow paths restrict access for building machines and vehicles. Because of these construction efforts, there are a variety of styles and sizes of buildings in the camp see related figure $3 \& 4$.

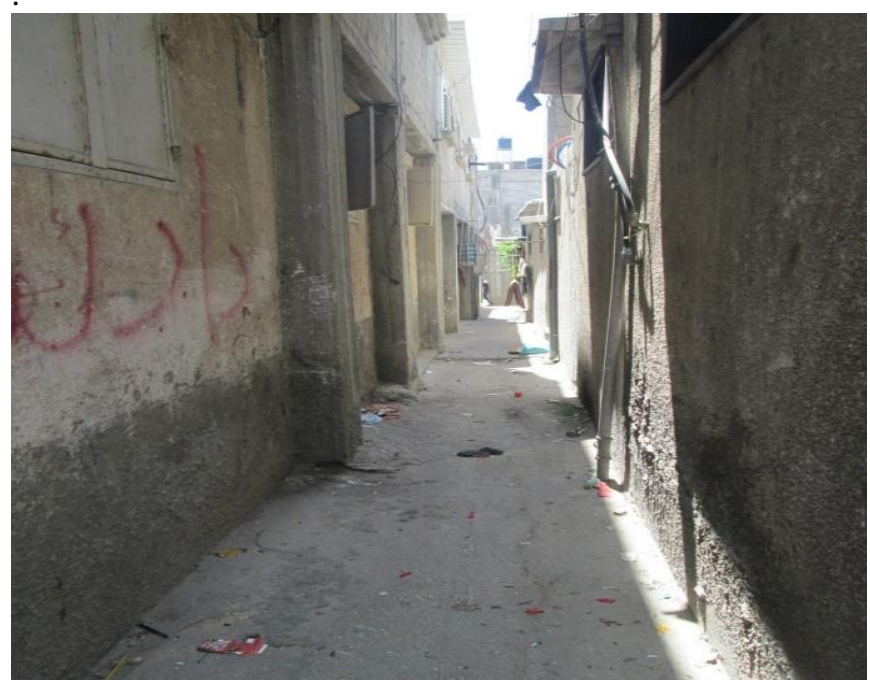

Figure 3: Different heights within the houses from the street Source authors, 2016.

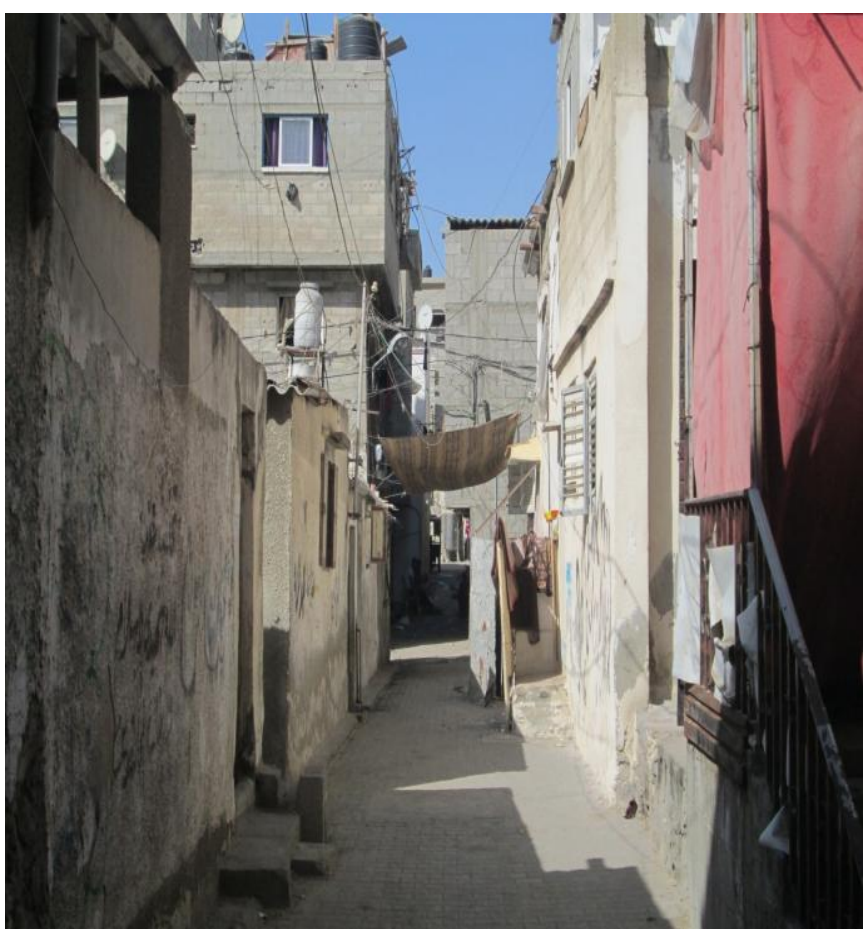

Figure 4: Jabalia camp poor roof materials, Source authors, 2016

\subsection{Gaza Strip reconstruction process from the view point of Palestinian experts}

we believe that the corresponding proportion of all reconstruction activities, with the affected areas, and the requirements of the local community as well, were based on the results of rapid surveys and studies conducted by the academic expertise and the executive directors in charge, in order to draw an action framework which might be considered as the main, and brilliant doctrine of post disaster reconstruction in the related field of studies. As a result, according to the Gaza situation, the assessment of the target community, and also cognition of the collective behavior of the affected community, is the main tools in order to choose appropriate approach toward the planning in the post disaster reconstruction tasks. As a matter of fact, in the local close cooperation between all stakeholders is necessary to achieve proper and sustainable solution to the current problems as their integrated role can maximize the available resources and convince all parties with the suggested solution as they participated in the decision [6].

\subsection{Population distribution}

Refugee camp populations vary from area to area, with the largest camp population residing in the Gaza Strip (more than half of all registered refugees), and the largest refugee camps $(107,415$ people live in Jabalia ). The increase in population in each Governorate till 2015 is mainly affected by three factors: natural growth of the existing population, immigration of returnees settling in the governorate and their natural growth until 2015 and the internal migration between the governorates. The distribution of returnees to the governorate differs according to the alternatives. In the plan immigration of returnees is programmed according to assumption that in 2005 the Palestinian State will be established with stable political, economic and social conditions. Palestine will be a free nation with control of the whole of Gaza and West bank, refugee camp populations vary from area to area, with the largest camp population residing in the Gaza Strip (more than half of all registered refugees), and the largest refugee camps 107,415 people live in Jabalia , [7]. The increase in population in each Governorate till 2020 is mainly affected by three factors: natural growth of the existing population, immigration of returnees settling in the governorate and their natural growth until 2020 and the internal migration between the governorates. The distribution of returnees to the governorate differs according to the alternatives. In the plan immigration of returnees is programmed according to assumption that in 2005 the Palestinian State will be established with stable political, economic and social conditions. The United Nation Resolution is the basis of solving the refugees problems .This means that all Palestinians will have the right to return to their homeland. The internal migration differs from one alternative to another as will be shown for each alternative:

\subsection{Overcrowding}

Overcrowding is a phenomenon characterizing most of the 8 Palestinian refugee camps administered by the United Nations Relief and Works Agency (UNRWA) spread out in the Agency's fields of operation, namely: Jabalia camp. There are three main interrelated causes for overcrowding:

- The dramatic population increase, while the land area allocated for camps remained fixed;

- Poverty which hinders people from moving out;

- Large family sizes living in shelters that generally do not exceed 9 square metres. Official figures indicate that the average family size is 4.5 in Gaza.

However, unofficial studies indicate the figure might be higher. Overcrowding is pervasive in most refugee camps 


\section{International Journal of Science and Research (IJSR) \\ ISSN (Online): 2319-7064}

Index Copernicus Value (2013): 6.14 | Impact Factor (2015): 6.391

and is manifest in the private and public domains. The private spaces of shelters are too small for inhabitants, while the public centers, such as schools and health clinics, are few and understaffed, relative to the population size and therefore are overcrowded. This situation generates social and psychological problems, including violence and physical abuse, especially directed towards women and children; early marriage and divorce, incest, the marginalization of children, women, youth, the disabled and the elderly. Overcrowding is also responsible for stress disorders, depression and anxiety.

Taking into consideration the political environment that surrounds the refugee question and the empirical constraints which hinder fundamental and macro-level changes, it is possible to deal with the social and psychological problems related to overcrowding by adopting simultaneously the following strategies:

To deal with the effects of overcrowding by selecting a specific problem area, identified by the community as resulting from overcrowding, such as the renovation of shelters, violence or early marriage and develop projects to address these issues. -To tackle the causes underlying overcrowding, by adopting a developmental approach that will have a long-term impact on the community; mainly by empowering and activating the existing local communitybased organizations, through training, material and financial support; as well as poverty alleviation schemes and incomegeneration projects. Gaza refugee camps suffer from tremendous overcrowding; having doubled their population since the 1950s without being allowed to expand their area, the population density is among the highest in the world. Expansion is difficult as the areas designated for refugee camps are limited and usually surrounded by urban areas. Housing in Gaza camps is very simple, while camps often resemble regular (lower-class) neighbourhoods for the urban poor [8].

\subsubsection{The cause of Overcrowding}

While "overcrowding" is both a cause and effect, it is possible to delineate the main direct causes of overcrowding in the Gaza Strip refugee camps. The causes are very important to take into consideration for policy-makers, donor countries and organizations working with refugees. As budgets allocated for refugees shrink, there is an increased need to examine these causes, in order to implement solutions and projects with long-term impact on the refugee community. In addition, causes and effects are linked and it is difficult sometimes to separate one factor from another, because they are so entangled. One of the effects of overcrowding, for example, is yelling and screaming at children, which has a ripple effect on the ability of children to study. However, these factors have been separated as much as possible to highlight the main issues related to this subject.

\subsection{Population density in Jabalia Camp}

The Gaza Strip has a high population density at 4,505 people per square kilometer, with 1.8 million inhabitants living in an area of 365 square kilometers. Approximately half of the population is children, and almost three quarters of the population registered Palestine refugees (see related figure5).

The annual refugee population growth rate for Gaza in 2012 stood at a high 3.5 per cent and is expected to decline only to some 3 per cent by 2020 (see related figure6). The inevitable increase in the population will pose further strains on access to affordable housing and services including electricity, water and wastewater treatment. Population growth and the high number of adolescents who will enter the labor force in the coming years also mean that the economy will have to grow in line to keep pace with the expanding labor force [8] $\&[5]$. The quality of the camps' physical environment cannot be separated from the refugees' quality of life. In Gaza an average of 49 per cent of camp shelters are in substandard conditions. Walls of refugee shelters are mostly structurally unsafe, poorly insulated and not water proof. Roofs are frequently irreparable and consequently in need of replacement. Ventilation is inadequate, and shelters are damp and musty, cold in winter and hot in summer. Many families are crowded into too few rooms and most of the roads are narrow, inaccessible and unlit. UNRWA plays an important roll thru theircamp upgrading programmes which called camp improvement started in 2004 In Gaza; camp improvement has become necessary to better the living conditions of residents and to improve environmental health. Comprehensive development work needs to be carried out inside and outside the camps to address chronic problems such as overcrowding, random expansion of buildings, unplanned land use, inaccessible roads and alleys and deteriorated shelters.

\subsubsection{Public Spaces}

It is important to note at the beginning of this section that the causes and effects of overcrowding in the Gaza strip camps specially jabalia are exacerbated. In this report, public spaces refer to areas such as streets, schools and other public centres such as health and community centres. In fact, due to overcrowding, almost all spaces become 'public'. The shelter or the 'home' is so close to the neighbors in most cases, that 'privacy' or the 'private domain' becomes a theoretical construct.

Percentage of substandard shelters in the camps

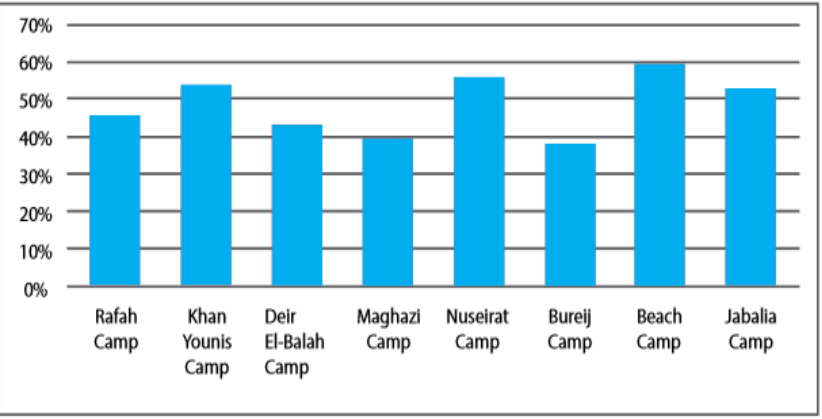

Figure 5: percentage of substandard shelters in the Camps, Source UNRWA statistic 2016 


\section{International Journal of Science and Research (IJSR) \\ ISSN (Online): 2319-7064}

Index Copernicus Value (2013): 6.14 | Impact Factor (2015): 6.391

\section{Refugee camp population per $\mathrm{km}^{2}$}

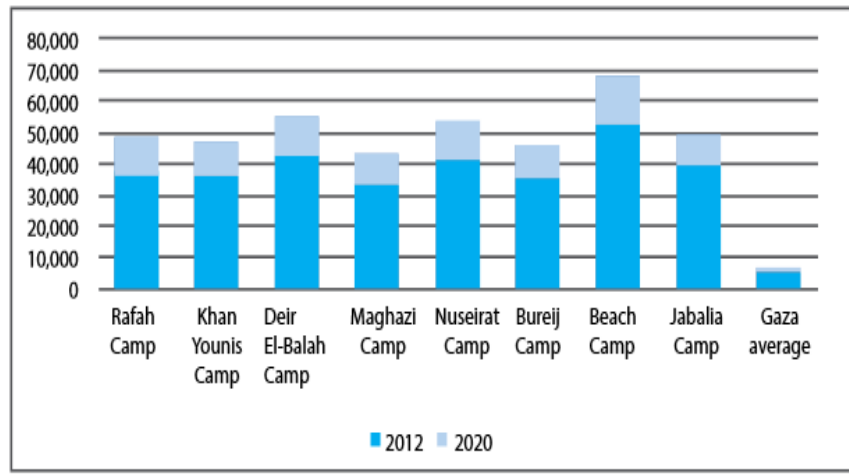

Figure 6: Refugee camp population Per Km2, Source

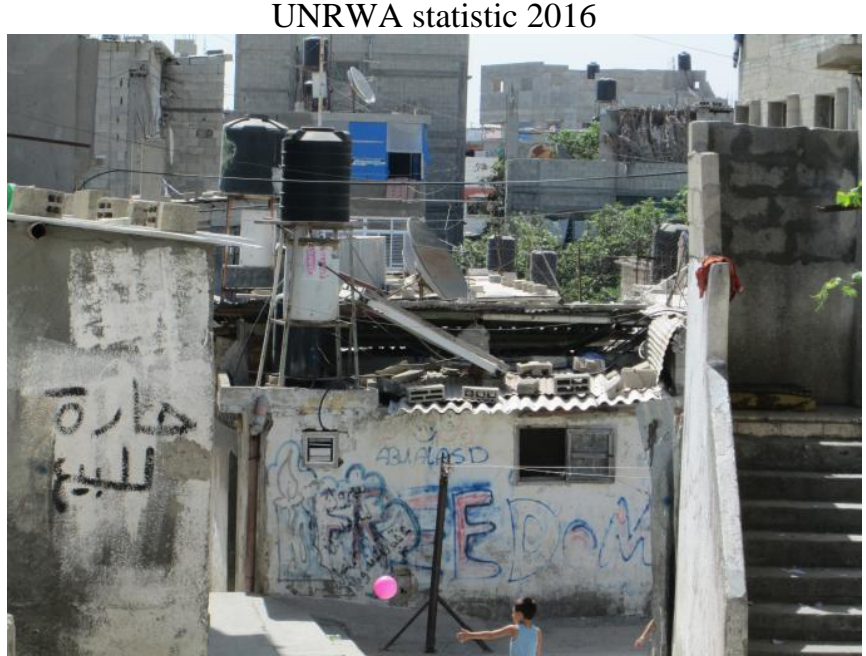

Figure 7: Open space area between houses at Jabalia Camp, Source authors, 2016

In addition, culturally, the dichotomy between the private and public domains are ambiguous. Issues and spaces considered 'private' in western societies may be very public in other cultures. Although many of the camp alleyways and streets are paved, there are many that still need paving and/or repair. In Jabalia camp, for example, it is a real problem, because the main streets are not asphalted and in the winter they turn into mud pools. More importantly, many of the shelters are on the same level as the streets, it is therefore not surprising that some shelters are flooded with dirty water in the winter. This situation forces the inhabitants of the shelters to sleep and live in a smaller corner of the house, until the water has been drained out. As for public services, they are not sufficient, especially garbage disposal and it is not uncommon to see children playing around overflowing disposal garbage bins. Although UNRWA provides regular sanitation and disposal services, the deficit and cutbacks in its budget hinders it from hiring more staff and employees to provide these services to a steadily growing population. Many of these disposal bins are placed in wider streets, at the entrances of camps or in areas making it accessible for collection

These areas are similarly attractive to boys who seek wider areas and spaces to play. Many of the boys (to lesser extent girls) are seen barefoot playing football and other games, due to lack of other spaces.
With the increase in population, people began to build vertically, second and third levels, usually accommodating sons and their families. As horizontal expansion is no longer possible in the majority of camps, the buildings are rising higher and higher. This situation means that the sun-light never enters into many of these shelters and there is no air ventilation, therefore shelters are very damp in the winter and humid in the summer. In addition to the health dimension, social problems are compounded as shelters push closer to one another and the neighborhood becomes overcrowded with large families, almost nullifying the concept of privacy and creating conflicts over space, children and intrusion. Some streets have become so narrow from over-building that it is sometimes difficult for more than one person to walk through. These issues are currently under discussion within the shelter cluster, including other temporary options such as prefabricated units (in certain circumstances), and techniques such as gabion baskets. Immediate repair and rehabilitation of shelters: restore decent living conditions for families whose housing units have sustained damage due to the recent bombing in the Gaza Strip, ensure the early and safe return of people to their homes, and reduce the psychological trauma and distress caused by displacement. Over 37,000 housing units with major to minor damages will be left unrepaired, and the families that called them home will have no place to return to [10].

\section{Sustainability in Gaza Strip}

Sustainable development is development that meets the needs of the present without compromising the ability of future generations to meet their own needs. Sustainable development means improving the quality of life while living within the carrying capacity of supporting ecosystem. The general definition of sustainable developments is development that delivers basic environmental, social and economic services to all residents of the community without threatening the viability of the natural, built and social system upon which the delivery of these services depends. The particular circumstances of Gaza a small, over population and relatively resource deficient and isolated area make most definitions of "sustainable development and the methods for assessing their attainment seem almost irrelevant. At our current situation it looks to be impossible to achieve sustainable development within a limited area such as Gaza Strip Governorates. At the present time, Gaza governorates gross density about 2,800 persons $/ \mathrm{km}^{2}$. According to the population forecast density is predicted to reach 6,100 persons $/ \mathrm{km}^{2}$ in 2015 . Will this be possible or sustainable? Historically, there was a large increase in the population during 1948 and later, because of the influx of refugees. The population was 65,000 inhabitants in 1945 and due to the war and the immigration of refugees, the population more than doubled by 1948 and by 1996 it was 16 times that of 1945[11]. If the increase of population had depended on the natural growth only, it would be another question, and sustainable development might have been a more realistic goal. Finally, one conclusion is that, according to available natural rescues and population needs, it is impossible to reach absolute sustainability in Gaza. However, the aim should be to work towards sustainability. 


\section{International Journal of Science and Research (IJSR) \\ ISSN (Online): 2319-7064}

Index Copernicus Value (2013): 6.14 | Impact Factor (2015): 6.391

\section{Result of the Study}

Overcrowding in the camps, lack of playgrounds and facilities for youth, adolescents and children means that streets are the primary places for play and interaction with peer groups. However, streets are primarily dominated by boys and male youth. Therefore, one major effect of overcrowding is that female children, adolescents and youth are confined in shelters, while boys and male youth dominate the camp alleyways and streets. Both situations foster carelessness and general low morale.

Schools suffer from overcrowding in classes, small playgrounds and absence of facilities for extra-curricular activities. Physical and verbal abuse of pupils is common and is the predominant form of discipline resulting from the inability of teachers to control large numbers of students, lack of teaching skills and general frustration.

Similarly, health centers are congested; doctors see an average of a hundred patients per day and very often more than that. Many sick people remain without proper care. Women, especially burdened with domestic responsibilities towards the extended family, including the elderly and disabled, suffer from fatigue, depression and anxiety, with no specialists or counseling services to help them. Women, including those who work are socially restricted in their movements, while men enjoy more freedom of movement in public spaces. In the private domain, shelters are overcrowded due to the large family size. Overcrowding in the shelters and the close proximity of neighbors, nullifies the possibility of any privacy or 'quiet time'. This has a ripple effect on all the members of the household, including: stress, incest, inability to study, beating of wives and children, quarreling and yelling. Quarreling with neighbors is also common, due to overcrowding. The lack and/or ineffective community centers catering to the needs of the various segments of society, such as the elderly, the disabled, women and youth, has compounded the problem of overcrowding by limiting the spaces available, mainly to the streets or shelters. Another effect of overcrowding and poverty is that they encourage early marriage to lighten the burden at home, which means pulling young girls out of school. In many cases, early marriages lead to early divorces. Similarly, many boys drop out of school, so that they can work to help their families financially, or because there is general neglect at home and school of their individual needs.

-Dominated Spaces. Boys: While you can see both boys and girls playing in the streets, in reality the streets are a male-dominated space. Girls may play in the street only until they are around nine years of age. For boys, streets have become the main play area for such games as soccer. Many times, such areas are where the garbage bins are collected and where children play barefoot, and this leads to health problems. Since 'space' becomes a contested area, boys often fight with one another over who has the right to play in a particular place. Parents complain that street playing pushes their children into delinquent behavior that there are no other activities in which growing boys can participate, whether they are sports, cultural or social activities, thus limiting their potential. Community responsibility is usually fostered in centers for adolescents and youth, at school and in volunteer work, but these are absent or too few to have a real effect on the majority of youth.

-Lack of Privacy and Noise, Due to overcrowded conditions and the closeness of shelters to one another, the noise levels are usually very high. Men, women and children complain that there is never a 'moment's peace'. If the family manages to keep the noise level down, the noise from the neighborhood is heard. This creates stress, especially for the sick, the disabled and students trying to study. Moreover, there is simply no place to be alone or to conduct a 'personal' matter without the scrutiny of many others. The lack of privacy leads to social control, enhanced by overcrowding. This affects all members of society. The shelters are so cramped and literally stuck together, it is almost impossible not to overhear the neighbors. This creates many problems among families in the same neighborhood. Children who play in the streets get into fights and adults are dragged into the conflict. Adults explained that they had to restrict and in a few cases sever relations with the neighbours to 'protect' their daughters from the young men living next door. Conflicts sometimes erupt, because the boys next door try to harass the neighbor's daughters. Overcrowding also means that neighbors fight over simple things like trying to clean one's home. Dirty water sometimes flows into the neighbor's house and this also often leads to 'not so neighborly fights'.

-The whole refugee community suffers from general depression in the sense that their expectations of the peace process were much higher than what has actually changed since the PNA relocated to the West Bank. The high unemployment rates, poverty and the belief that the 'outsiders from PLO' took over political power and authority, to which they were entitled adds to a sense of disappointment and uncertainty regarding their future.

School Drop Outs, Families with six or more children of varying ages cramped in one or two rooms find it almost impossible to provide attention to all the children and follow up on each child's work at school. Some parents are themselves illiterate and hence cannot provide support at that level. For some parents, education is not an urgent priority in their world view, especially for girls, who are expected to get married. Education in their perspective may be an obstacle, rather than an asset. This problem is mirrored in schools. With overcrowded classrooms, teachers are stressed and can hardly manage to go through the required curriculum, much less to pay attention to the individual needs of their students. Dropping out of school at grade nine is not uncommon among girls. UNRWA schools do not provide secondary education and once they graduate many girls are not encouraged to continue with secondary schools. The reason is usually that parents do not have the means to spend money on transportation and other school expenses for all children. Generally, parents would rather spend the money for school on boys than on girls. In addition, many of the parents interviewed expressed their unwillingness to allow their daughters to take public buses and go outside the camp, even for the purpose of studying fearing 'gossip' and 


\section{International Journal of Science and Research (IJSR) \\ ISSN (Online): 2319-7064}

Index Copernicus Value (2013): 6.14 | Impact Factor (2015): 6.391

'slander' from the larger community. Consequently, the incidence of girls being pulled out before completing secondary levels is high and many get married even before they turn eighteen.

The Disabled, One important effect of overcrowding is neglect, especially for the most vulnerable in society. Centers for the disabled are limited and many of the volunteers in refugee camps, mainly community members, are not trained professionally to deal with the disabled, as is the case in jabalia camp. The disabled, especially children, suffer from neglect because there are not enough centers and poverty hinders families from sending them to private rehabilitation centers. There are often too many children at home to leave time for adequate attention to the disabled member of the family. In addition, lack of sufficient awareness about disability in the community, reflects itself in neglect and sometimes the marginalization of the disabled. In fact, in some cases, parents do not like to publicize they have disabled children. Some of these children are taken out from the school system and stay at home with no proper care or therapy. In most cases this exacerbates their condition.

The Elderly, In general, the elderly live with one of the sons, usually the eldest. In overcrowded conditions, the elderly live together with the members of the son's family, sometimes with other unmarried brothers. However, daughters-in-law have their own family to care for and hence cannot always attend to the needs of the elderly. The situation is stressful for both generations, as daughters-inlaw feel they are squeezed between the younger dependent children and the elderly people living in the house. Moreover, simple tasks such as food preparation, bathing and clothing the elderly who are sick also fall on the shoulder of the younger women. Conflicts are common between the two generations, especially in cases when the elderly feel they are being neglected or have differences in opinion regarding how children should be raised.

In other cases, the elderly live alone, either because most of their children have moved outside the camp and/or because the shelter of their son is too small, his family is too large or he does not have the financial means to accommodate his parents. In this case the parents are able to maintain their own place, but again, the main problem is neglect. Field visits indicated that the shelters of the elderly are in bad need of renovation and reconstruction and cases have been sited when the roofs simply fell in on the heads of the elderly. In the past, UNRWA was able to extend its shelter rehabilitation program beyond those enrolled in the Special Hardship Case program. The elderly are not identified as a priority segment by UNRWA as are the disabled, women and youth. Therefore, programs geared to the elderly are diminishing. In some camps, the local mosque provides two hot meals per week to the elderly who have no one to look after them.

\subsection{Priorities and recommendation}

The most urgent priorities in refugee camps are:
1)Renovation and expansion of shelters, improvement of the infrastructure, especially the asphalting of streets and the drainage systems and networks.

2)Renovations of schools by adding classrooms to absorb the increasing number of students. If possible, support the building of new schools. Improve facilities within schools, such as introducing computer labs and libraries.

3)Increase the number of health centers and health staff.

4)Introduce programs for the community in gender issues to help raise the awareness of the community.

These again have to be implemented sensitively, as many fear that such programs aim at 'westernizing' the local community. Programs such as 'Family Health' could include lectures on violence, abuse and incest. Most importantly, it is important to activate the community-based organizations. However, initial material, financial and logistical support is needed, especially at a time when there are severe cutbacks in UNRWA affecting the refugee community as a whole. Short-term investment in the activation and support of the community to alleviate problems associated with overcrowding will in the long run assist them to become self-supporting and autonomous. Training in humanresource planning and managing local organizations is important. It is therefore recommended that community leadership be fostered, especially from among the youth, providing them with training in managing, planning and implementing programs. Most importantly, it is necessary to provide training in community mobilization and encourage volunteer activities.

Most of the refugee camps in the West Bank and Gaza have universal needs that will mitigate the effects of overcrowding. However, there are also specific needs which must be taken into consideration when implementing projects. These specific projects may be based on the following list of recommendation and priorities which are the sum total of the major and most urgent problems resulting from overcrowding.

\subsubsection{Places and Spaces}

Improved infrastructure diminishes the effects of overcrowding the social and a psychological effect of overcrowding is exacerbated by the low standards of the infrastructure in camps. In addition to the pressures brought about by spatial density in the camp and overcrowding within shelters, the environmental factor is depressing and demoralizing. In most camps the smell of dirty water leaking from open drainage and sewer pipes permeates the air and is compounded by the smell of uncollected garbage bins. In some camps sewer drainage systems or networks have not been extended. In many alleyways in refugee camps, it is difficult to walk through, without having to step into the dirty water or a hole. This environment is the larger "playground" for refugees and especially children who spend most of their childhood in the streets, usually for lack of proper playgrounds and centers. Consequently, it is not surprising that refugees point out that this is an urgent need for improvements in the overall infrastructure of the camps. Such improvements should include the asphalting of streets, which turn into mud pools in the winter, as is the case in Jabalia camp. 


\section{International Journal of Science and Research (IJSR) \\ ISSN (Online): 2319-7064 \\ Index Copernicus Value (2013): 6.14 | Impact Factor (2015): 6.391}

5.1.2 Shabby and Narrow Shelters need Renovation and Expansion, An urgent priority that cuts across all camps is shelter renovation, reconstruction and expansion of housing units. By November last year, UNRWA's Self-Help approach to shelter rehabilitation was responsible for the rehabilitation of $60 \%$ of shelters for those enrolled in the Special Hardship program. If one considers that the SHC covers approximately $6 \%$ of the total refugee population, it becomes clear that the number of people who were able to get help is minimal relative to the needs. In addition, the regulations surrounding who is eligible for the SHC program is extremely stringent, leaving out many needy families who are unable to afford the rehabilitation of shelters. Nevertheless, the example of UNRWA's approach is a good one to emulate.

\subsubsection{Larger classrooms, more facilities}

Many of the UNRWA schools run on a double shift and in 1999, the Agency began to build new schools and maintaining others, especially in Gaza, where the average class size fifty pupils per classroom. Yet, in view of shrinking budgets, these efforts despite their significance are insufficient and both the West Bank and Gaza are in need of more schools to lower the numbers in classes. However, there are short-term projects which may enhance the school environment, such as renovations on existing schools and the building of extra classrooms. Pupils also suffer in that many of these schools have small playgrounds which are congested with students at break time. There are also no spaces for extra-curricular activities, libraries are too small and books are few and old, in some there are no libraries at all.

There is a need to provide counselling services to students who simply do not have anyone to turn to for academic support or to counsel them. There are many students in higher preparatory grades who do badly in school and special education programs will be of tremendous help. Also important are programs upgrading the skills of teachers in new methods of teaching.

5.1.4 An Improved Health Care Program and More Health Centers In this area, it is important to provide financial and logistical support to health centers. In many camps there is only one center serving thousands of people, usually the camp population and surrounding area. Secondly, the health staff are overworked. Doctors as mentioned earlier sometimes have to see 150 patients per day and many patients return home without being seen. Due to the pressure on the health centers in camps, many refugees are compelled to seek private health care adding to their financial burdens. Therefore, it is important to find ways to increase the medical staff.

In addition, female doctors are few and many women avoid male doctors. Hence, there is a need for female specialists, especially in women's health issues, such as childbearing, gynecology, psychologists and psychiatrists. Clinical psychologists are very few in the camps. Women and youth are especially in need of counselling. Some of the women interviewed revealed they were taking anti-depressants, but usually there are many social problems left unattended and the antidepressants do not solve their problems at home and in the community.

\subsection{Programs for Marginalized Segments of Society 5.2.1 Children and Adolescents: Playgrounds and Children's Programs}

The absence of playgrounds for children is a real problem in all camps. In earlier decades and before concrete totally replaced gardens and filled the available spaces in refugee camps, children played in front of their homes. On the one hand, the little gardens or spaces provided an outlet for families living in shelters, relieving the stress inside the shelters and on the other hand, it offered children a place to play more safely under the scrutiny of parents and neighbors. Playgrounds are a priority cited by all those interviewed and in all camps. The main problem is that in many camps the space is simply unavailable or limited. Creative solutions are required to find the best way to create play centers for children. In larger camps, more than one play area/playground/park is needed. Although spaces are limited, such as in Camp No. 1, alternatives are possible around camps, if not within them.

Adolescent girls and boys suffer from being at an age when they are neither 'children' nor 'youth' in official and international definitions. Adolescent girls, especially, do not have any places to go and the concept of 'entertainment' is simply absent or restricted to visits with relatives and television. Many of them do not leave the camp boundaries, except on rare occasions. Ten or twelve year-old girls cannot play in the streets like their brothers and neither can they join in the women's centers providing various programs. This age group complains that all they do is stay home and watch over their younger siblings. It is therefore, imperative that 'girls' clubs providing indoor sports, social and cultural activities be established. Similarly boys in this age group need such centers. When many adolescents are facing problems in schools, such clubs or centers could provide assistance and counseling for slow-learners. This would encourage many parents to allow their daughters to participate.

\subsubsection{Youth: Youth Centers, Activities and Programs for Young Women}

The interviews showed that youth, who constitute a large percentage of the population, are stereotyped as a 'dangerous' and 'uncontrolled' segment of society. With low educational standards at school, limited spaces and centers to enhance their potential, they feel lost and neglected. Therefore, it is important that programs and centers catering to their needs should be established. These should include extra-curricular activities ranging from sports to computer training as well as cultural and social activities, including art, theater and music. Some of the UNRWA community based youth centers are beginning to include young women. However, these are too few and the social and cultural environment in most camps does not encourage such mixed centers. Therefore, centers exclusively for women are needed.

Many young women who may be categorized as 'youth' are also married. It is not uncommon to meet women at 18 or 19 


\section{International Journal of Science and Research (IJSR) \\ ISSN (Online): 2319-7064}

Index Copernicus Value (2013): 6.14 | Impact Factor (2015): 6.391

with two or three children. Therefore, programs for young women should integrate assistance in providing child-care and awareness raising programs on family planning and health issues. The lack of these spaces also forces the younger generation in seeking alternative ways to express their potential and identity. Many students, who do not do well in school, could greatly benefit from such centers that provide group solidarity. On the social level, cultural and social clubs provide an outlet and an avenue for personal growth and development.

\subsubsection{Women: Women's programs, activities and outreach activities}

Programs directed at raising awareness of women's rights are important, however, some of these programs have failed in the past because they did not take into consideration the conservative environment which exists in many camps. Therefore, these issues could be introduced within larger programs such as 'family planning', legal counseling and general health as the overall framework and within that provide awareness on gender issues, physical and psychological abuse, child rearing and skills training. Middle-aged and older women, especially those who are not working, comment that there are no places for them to go. The women's centers capacity is limited and therefore it is recommended that the women's centers be expanded.

More importantly, it is important to establish networks that will reach women in their homes, as there are many who cannot leave their homes for various reasons. Some of these women suffer from depression, abuse or health problems and they remain without support, because they cannot reach the center. Thus approaches which aims at reaching out towards the community will be more successful than expecting the community to reach to the center, at least until the centers are well established.

There is a need to provide community awareness programs, directed at the family as a whole. Many women for example, point out that it is the men who need education on the problems they face as women in the family and society. Men point out that women do not understand the pressure placed upon them to be the primary providers for extended families. Therefore, it is important to include programs directed at the family as a whole and in relation to the local community, its needs and problems.

\subsubsection{Activating Local Community Organizations}

The primary problem with existing services and organizations is that these are insufficient and in many cases ineffective. A small percentage of the community benefits from many of the available services. Moreover, many of the programs are targeted at one segment of the community and the family as a unit, for example, is neglected. This latter issue is significant, in that in Palestinian society the family is the basic unit of society and the individual is closely entangled in family relations. There is also overlap in services due to lack of coordination by the local and international organizations providing services in camps. In some cases, the programs are not based on local priorities and identified needs, but respond more to international and donor prerogatives and priorities. Taking into consideration the political and empirical constraints and realities, it is possible to mitigate the effects of overcrowding on refugees, by adopting the two suggested approaches simultaneously:

To select problem areas identified as an urgent need (Jabalia) by refugees, community workers, NGO activists and others who are working in camps and develop projects which address particular problems. An important approach is to activate and empower the local community by providing various kinds of support to the existing community organizations, which are currently not very effective.

There are numerous local community organizations, however, many of these are ineffective and need support, both in terms of training in skills and management and materially in terms of equipment and funding. Overlapping services is another problem and this often means that one problem area is covered by more than one organization, while other areas are neglected. Consequently, training in human resource development and planning is important, especially for employees and volunteers working in local committees. Another recommendation is the creation of committees representing all community based organizations within refugee camps to continuously identify and prioritize problems; to plan, coordinate and implement programs and projects aimed at the community as a whole.

Another priority area is to upgrade the knowledge and skills of employees and volunteers, such as care for the disabled; seminars and courses for trainers and to develop local leadership skills. It is important to provide logistical, material and financial support for short-term projects that will help mitigate problems associated with overcrowding. However, it is equally important to simultaneously support projects which empower the community, by providing training and logistical support to the community organizations who will eventually be able to tackle the problems associated with overcrowding more efficiently. Finally, while short term projects may help mitigate and solve some of the issues related to overcrowding, the political issues and general poverty are two major factors which continue to reproduce overcrowding in refugee camps especially in Jabalia refugee camp.

\section{References}

[1] MOPIC, (1994): Gaza Environmental Profile, Part I. Environmental Planning Directorate (EPD), Ministry of Planning and International Co-operation (MOPIC), Gaza, Palestine.

[2] Badawy Ussama, 2012 ;( Palestinian Contemporary Architecture, analysis of the current situation in Gaza Strip), published in English by the Fourth International Engineering Conference (IEC4), 16 October 2012, IUG

[3] Jaber, A. and Nasser, A. (2007) : Assessment of solid waste dumpsites in Gaza Strip. Gaza Strip. JICA \& EQA.

[4] UNRWA fact sheet various years 2008,20012,2015. UNRWA field office Gaza public information

[5] Badawy Ussama, und Waltz Victoria. 1999 : Actually Wohnungsbauprojekte in Gaza streifen-Actually Housing Condition and Projects in Gaza strip-Published 
in Bauwelt International journal, No, 9. 1999. Pp.422428.

[6] Badawy Usama and Victoria Waltz 2014 ,Housing Conditions and Upgrading of the Refugee Camps in Palestine West Bank and Gaza Strip, Edition: 456789-, Publisher, Centre of Planning and Architectural Studies Cairo Egypt, ISBN: 67974378.

[7] UNRWA fact sheet various, 2014. UNRWA field office Gaza public information

[8] Shelter/NFI Cluster, Guidelines for the Reconstruction and Rehabilitation of war affected individual housing in the Gaza Strip, Gaza, August 2009.

[9] Humanitarian Policy Group, Sanctuary in the city? Urban d7isplacement and vulnerability in the Gaza Strip, December 2012.

[10] Badawy Ussama, 2012 Community feedback for Palestinian refugee camps reality, need and opportunities Khan Younis camp as a study case.), published in English by Scholars press 2016.

[11] UNRWA fact sheets various, 2016. UNRWA field office Gaza public information

\section{Author Profile}

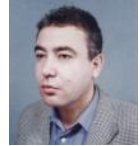

Professor Dr. Usama Ibrahim Badawy s B.S and M.S. degrees from Technical, University of Berlin Architectural Departmernt1991 ,PhD in Urban Planning from Technical University of Berlin 1997 .Former Professor of Architecture, Birzeit University, Works currently by the United Nation . Professor. Badawy has 26 years extensive experience in design, urban planning projects and as professor in various national and international universities.

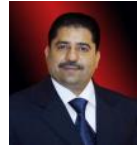

Assistance Professor Dr.Ra'ed A.Salha B.S degrees from University of King Abdul Aziz 1984 , M.S. from the Arab League University of Cairo1994, PhD in Geography and GIS from the Arab League University of Cairo 2003 .Currently works as Assistant Prof at Islamic University of Gaza since 17years,Faculty of Arts, Islamic University , Geography and GIS Department

Assistance Professor Dr.Muain Qasem Jawabrah B.S and M.S. degrees from Politecnico Di Milano 1987 Inderizio Projetazione Architettonica Ph.D. in Architectural from (RWTH Aachen Germany) 1997. Recently Associate professor of Architecture, Birzeit University, Palestine

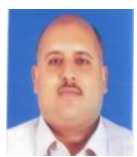

Eng. Amjad Jarada is B.S degrees from Islamic University of Gaza 2001. M.S. from Islamic University of Gaza 2004. Ongoing $\mathrm{PhD}$ in Civil Engineering (Hydraulic \& irrigation Department) Cairo University. Currently works as OiC Head Design Division UNRWA and also as a researcher in infrastructure planning and development.

Mr .Mohammed A.EL Hawajri is B.S degrees from Islamic University of Gaza 2008, M.S. from Islamic University of Gaza 2016 researcher in Geography subjects, works currently as teacher by the ministry of 